\title{
Cuando la mano de obra se subleva: estrategias terratenientes \\ durante la reforma agraria chilena (1964-1973)
}

\author{
Mathias Órdenes y José DíaZ-Diego
}

PALABRAS CLAVE: reforma agraria, estrategias terratenientes, conflictos sociales, centro y sur de Chile.

\section{CÓDIGOS JEL: D74, N56, R19, 017.}

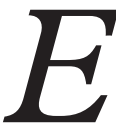

l presente artículo tiene por objeto describir y analizar las estrategias de los patrones de fundo de la zona centro-sur de Chile para enfrentar a sus trabajadores movilizados durante la reforma agraria. Se analiza la composición tradicional del mundo rural, los cambios producidos en distintos momentos del escenario sociopolítico y la organización sindical y gremial de trabajadores y dueños de fundo como factores claves en la elaboración de estrategias terratenientes. Entre ellas, se destacan acciones inéditas, como la unidad gremial, un discurso contrario pero propositivo frente a la reforma agraria, la búsqueda de acuerdos con el movimiento campesino, la constitución de una alianza con el sector superior del inquilinaje y el recurso jurídico, sin perder de vista el ejercicio de la violencia. A partir de la revisión de fuentes bibliográficas, documentales y archivísticas, se amplía la mirada respecto del periodo reformista, tradicionalmente centrada en la lucha interclasista y el enfrentamiento politico y laboral, incorporando ahora a este relato historiográfico variables de negociación, coalición y modernización. 


\section{When labour rebels: landowners strategies during the Chilean agrarian reform (1964-1973)}

\section{KEYWORDS: land reform, landowners' strategies, social conflicts, Central and Southern Chile.}

\section{JEL CODES: D74, N56, R19, 017.}

he object of this article is to describe and analyze the strategies landowners used
against mobilized workers in south-central Chile during the agrarian reform.
Key aspects analyzed in the development of landowner strategies include the traditional composition of the rural world, the changes occurring in the socio-political panorama over time, as well as workers' unions and landowner organizations. Along with the potential for violence, unusual actions included patron organization unity, a propositional discourse opposing agrarian reform, a search for agreements with the peasant movement, and the establishment of an alliance with higher-level legal and tenant resources. A review of bibliographic, documentary and archival sources offers greater understanding of the reformist period. It has traditionally been conceptualized through a historiographic narrative of interclass struggles and political and labor confrontation, but here incorporates variables that include negotiation, coalitions and modernization.

Recepción: 2016-02-29 • Revisión: 2017-01-27 • Aceptación: 2017-02-06

Mathias Órdenes es historiador, doctor en Procesos Sociales y Politicos en América Latina e investigador del Núcleo Científico Tecnológico en Ciencias Sociales y Humanidades de la Universidad de La Frontera. Dirección para correspondencia: avda. Francisco Salazar, Universidad de La Frontera, 01145 Temuco (Chile). C.e.: mathias.ordenes@gmail.com

José Díaz-Diego autor de correspondencia, es antropólogo, doctor en Desarrollo y Planificación Territorial y profesor asistente de Antropología Social en la Universidad Católica de Temuco. Dirección para correspondencia: cl Manuel Montt, 56, Campus San Francisco, Departamento de Antropología, Facultad de Ciencias Sociales, Universidad Católica de Temuco,Temuco (Chile).C.e.:jose.diaz@uct.cl 


\section{INTRODUCCIÓN}

Las presiones norteamericanas para implementar reformas estructurales en la propiedad de la tierra a través de la Alianza para el Progreso reactivaron la vieja discusión sobre reforma agraria en América Latina, que hasta la década de 1960 se mantenía a la espera de «mejores condiciones». Pronto, la reforma se convirtió en tema nacional cuando el Estado se impuso, como claro objetivo para el avance del desarrollo industrial, la modernización del sector rural, considerado el más atrasado y postergado del país. Tal transformación implicaba el logro de varios objetivos a corto y medio plazo, asociados a la modernización del campo, el aumento productivo, la mayor participación del campesinado en el consumo nacional y la corrección del desequilibrado reparto de la tierra (Gómez, 1982: 9-15; Santana, 2006:191-196).

Estos lineamentos generales, aunque bastante consensuados, no estuvieron bien definidos al comienzo. La aceptación de las premisas básicas que sustentaban la reforma no implicó acuerdos sobre su grado de profundización, por lo que los conflictos más serios se desarrollaron respecto del alcance, ritmo y movilización social que involucró su implementación en cada gobierno.

A partir de 1967 y bajo el gobierno demócrata cristiano de Eduardo Frei M. (19641970), la expropiación y reparto de tierras entró en una etapa más activa que puso fin a la moderada reforma agraria acometida por Jorge Alessandri R. desde 1962, conocida como reforma de los Maceteros por el escaso número de fincas afectas. Luego, al llegar el gobierno de la Unidad Popular (UP) de Salvador Allende (1970-1973), experimentó una profundización y aceleración, que coincidió con un momento de gran demanda y agitación social. De 1964 a 1970, la reforma afectó unas 3.564.553 hectáreas, mientras que de 1970 a 1973 a unas $6.401 .315^{1}$, lo que significó en total la expropiación del 58,7\% de la tierra de riego básico, el $43 \%$ del secano arable y el 65,8\% de secano no arable (Barraclough \& Fernández, 1974: 85; Gómez, 1982: 37; Huerta, 1989: 327).

Es evidente que, durante este proceso, los terratenientes tuvieron que enfrentar la amenaza de la pérdida, tanto de sus tierras como del control de la mano de obra. El desafío fue mayúsculo, pues tuvieron enfrente al Ejecutivo, a las organizaciones campesinas e incluso a los partidos de oposición política, como la Democracia Cristiana, que buscaron en la escasa tierra que llegaba al campesinado un arma arrojadiza contra Allende. Como

1.Según la Oficina de Planificación Agrícola (ODEPA), esta cifra fue inferior: 5.770.000 hectáreas (Boletín Agroestadístico, 1974, núm. 16). 
si fuera poco, a lo anterior se sumó una desfavorable regulación de precios de los productos agrícolas dirigida desde el Estado ${ }^{2}$.

El proceso gatilló la constitución de un momento histórico y un espacio sociopolítico abierto a las disputas entre los actores por el control de la propiedad y la construcción de hegemonía (Purnell, 1999: 12) ${ }^{3}$. En el plano ideológico, ello implicó la disputa por la construcción e instalación de categorías asociadas al poder (tales como desarrollo, modernidad, justicia, orden, patria, sociedad, doctrina social, etc.), con el objetivo de instituir, normalizar y sedimentar ciertas prácticas y discursos sociales y políticos (Sánchez, 2012: 103), que en el fondo ponían en tensión el éxito y el control hegemónico de proyectos históricos que iban en direcciones opuestas: el proyecto empresarial terrateniente, el proyecto de Estado desarrollista con Frei y en vías al socialismo con Allende, y el proyecto reivindicativo campesino, con una variante etnoterritorial en la zona mapuche. La interacción entre estos proyectos fue contenciosa y a la vez colmada de desajustes y fricciones internas, sin excepción ${ }^{4}$. De esta forma, la reforma agraria se constituyó en un espacio de articulación contingente de la política donde la hegemonía fue resistida, negociada y redefinida (Sánchez, 2012: 104). Es más, se sostiene que la posterior polarización del sistema de partidos provocaría tal divergencia que tendió finalmente a la mutua aniquilación (Garretón \& Moulian, 1983).

Parte sustancial de la literatura sobre la reforma agraria chilena nos remite a la violencia patronal, a la represión de Estado y, más recientemente, a los grupos subalternos y sus relatos, lo que implica, obviamente, una preocupación por el conflicto de clase en torno al gobierno de Allende y al posterior golpe de Estado de 1973. Relacionado con ello, una parte importante de los estudios sociales e históricos sobre la reforma agraria chilena han caracterizado a los grandes y medianos propietarios agrícolas como sujetos

2.A partir de 1932 se aplicarían un conjunto de políticas destinadas a estimular la industria nacional, como la importación y regulación de precios de productos agrícolas de primera necesidad. Esta intervención habría favorecido el crecimiento industrial de la zona central en perjuicio de los productores del sur (ALMONACID, 2009; PINTO \& ÓRDENES, 2012). La reforma agraria agravó la intervención, por lo que los terratenientes transmitieron sus quejas a los gobiernos, acusando un abandono forzado de las faenas agrícolas.

3.Sobre hegemonía, hemos utilizado las tesis de Mallon entendiendo este campo social como un espacio siempre abierto a las disputas, búsqueda de legitimación y orden social por parte de las elites e incorporación parcial de los intereses de los dominados (véase más en MALLON, 2003: 77-108).

4.En el caso de los grupos subalternos, Mallon sostiene que cuando intentaron transformar el régimen hacendal y Estado oligárquico, también adquirieron un compromiso crucial con la transformación de sus propias organizaciones políticas para la conformación del movimiento campesino (MALlON, 1994: 1491-1515). Sobre las disputas internas al interior de los sectores conservadores, véanse WRIGHT (1982), CAMPERO (1984) y OsZLAK (2016). 
que frente a la amenaza de la pérdida de sus tierras acudieron a las armas y reaccionaron con virulencia contra campesinos, indígenas, izquierdistas y funcionarios del Gobierno. Junto con fijar en el imaginario social esta representación de los agricultores como violentistas, gran parte de la literatura ha invisibilizado o, por lo menos, no ha dado cuenta con detalle de otras formas de oposición terrateniente en este período de gran agitación. Igualmente, se han tratado poco las particularidades de cada zona del país y los matices que presentó la coerción patronal, en muchas ocasiones producto de tomas ${ }^{5}$ y expropiaciones repletas de irregularidades administrativas ${ }^{6}$. Esta producción académica, aunque bien fundada, sigue siendo parcial, lo que requiere avanzar en los estudios de los dueños de la tierra para alcanzar la comprensión más integral de una realidad que se muestra, en palabras de Max Weber (1985), siempre infinita y compleja ${ }^{7}$ (Díaz-Diego \& Órdenes, 2016).

Por lo anterior, consideramos de interés historiográfico y antropológico analizar dos cuestiones vinculadas, tanto al mundo latifundista como al contexto sociopolítico de la época. Nos referimos, en primer lugar, a la capacidad de los terratenientes y sus organizaciones gremiales para elaborar distintas estrategias con las que enfrentar, en cada período de la reforma agraria, a sus adversarios políticos: el campesinado movilizado, las autoridades de gobierno y los partidos de centro e izquierda.Y, en segundo lugar, a las diferencias y similitudes del fenómeno, poniendo mayor atención al centro-sur de Chile y en él, especialmente a La Araucanía. Lo hacemos por cuatro motivos: en este espacio las movilizaciones campesinas fueron más violentas, lo que concitó mayor preocupación en la prensa, a diferencia del Norte Chico o las provincias del sur austral, donde la situación estuvo relativamente más controlada. En segundo lugar, en el centro-sur del país se constató mayor influencia de la Sociedad Nacional de Agricultura (SNA), cuando no de sus asociaciones gremiales de ámbito regional. En tercer lugar, las características similares en la estructura latifundiaria y de inquilinaje en ambas zonas nos ayudan a orientar nuestro análisis, considerando, además, a los mapuche en La Araucanía, quienes dieron al episodio un cariz etnocultural que evidenció una realidad más compleja.Y, por último, la mayor cantidad de estudios nos permiten reflexiones más

5.En Chile, se conoce como toma a la ocupación de una propiedad por parte de terceros, generalmente en escenarios de reivindicación social o territorial.

6. Archivo del Subdepartamento de Tenencia de Tierras y Aguas, Servicio Agrario y Ganadero, División Jurídica (ASTTA-SAG) de Santiago, fondo CORA, carpetas, 2373 y ss. Véanse también, FONTAINE (2001) y CAMPERO (1984: 31-88).

7.Al respecto, se ha demostrado que el enfoque unidimensional de la política nacional oscurece procesos profundamente complejos, como son las formaciones ideológicas a nivel local y las alianzas políticas interclases, y cómo éstas pueden determinar irrevocablemente el curso de la política nacional, especialmente en momentos de grandes movilizaciones sociales (GUARDINO, 1996). 
informadas, a diferencia de lo ocurrido en otras provincias, donde se cuenta con menos antecedentes ${ }^{8}$.

Observamos el proceso histórico como un campo concreto y complejo de luchas sociopolíticas, algo parecido a un tablero de ajedrez en el que cada pieza se mueve dentro de un marco de alternativas racionalizadas a priori. Por ello, analizamos las estrategias terratenientes y de sus organizaciones gremiales teniendo presente sus motivaciones y que las consecuencias de sus acciones no pueden comprenderse sino en relación con los demás actores y con el ritmo de la contingencia sociopolítica. Este enfoque nos obliga a distinguir, por lo menos, cinco cuestiones que nos ayudan al análisis de las estrategias terratenientes y sus instituciones: en primera instancia, las condiciones sociopolíticas en que se encontraban los distintos tipos de mano de obra campesina y los terratenientes en los momentos previos a la reforma agraria (factor denominado heterogeneidad estructural) y las posiciones sociopolíticas que fueron adoptando como actores cuando ésta se puso en marcha; en segundo lugar, las movilizaciones del movimiento campesino y mapuche-campesino en La Araucanía; en tercer lugar, las presiones del Estado sobre el sector terrateniente; en cuarto lugar, el ritmo y grado de profundización que fue tomando el proceso en distintos momentos de los gobiernos de Frei y Allende; y, por último, las similitudes y diferencias más significativas entre la zona central y sur de Chile. Más allá de agotar la totalidad de posibilidades analíticas, pretendemos avanzar en lo relativo a la diversidad de fórmulas con que los dueños de fundo afrontaron esta convulsa época, aproximándonos a las estrategias de mayor impacto espacial, temporal y sociopolítico.

Respecto de los trabajadores rurales, las fuentes que presentamos permiten sostener que una parte cualitativamente importante de los inquilinos acomodados y otros colaboradores se pusieron del lado del patrón y rechazaron la reforma a fin de mantener privilegios; en cambio, el mayor número de minifundistas, inquilinos pobres y asalariados afuerinos formaron parte del movimiento campesino que confrontó al patrón. Para el caso de La Araucanía, un número no calculado de población mapuche que trabajaba como inquilinos, dadas las condiciones históricas de la región, se debatió entre sumarse a la reforma agraria y apoyar al movimiento campesino-indigenista o, por el contrario, permanecer fieles al patrón, dotando así de mayor complejidad sociopolítica al período. Los archivos describen casos en ambas direcciones.

8.Sobre la provincia de Llanquihue pueden consultarse los trabajos de Felipe SÁNCHEZ BARRIA (2012 y s.f) y sobre el valle del Choapa (en el Norte Chico) el de Igor Goicovic (2015). Ambos autores coinciden en la falta de estudios sobre historia agraria regional. 
Asimismo, también se puede señalar que previo a invocar la intervención del ejército para la «restitución del orden», los terratenientes y sus gremios idearon sin mucho éxito otras estrategias. Como explicaremos, por primera vez en la historia de Chile estas actividades lograron la unión de los gremios patronales de la zona central y sur, formando una gran fuerza sociopolítica en torno a discursos y esfuerzos modernizantes y, a la vez, tendentes a la negociación y formación de alianzas y coaliciones.

De esta forma, coincidimos con Oszlak (2016) cuando sostiene que los sectores conservadores enfrentaron la reforma mediante el empleo de seis tipos de estrategias que pusieron de manifiesto el alcance de sus recursos de poder: 1) la consolidación, que tuvo por objeto comprometer la mayor cantidad de recursos posibles como actor social, integrándolos y empleándolos de tal modo que el resultado incremente las posibilidades de enfrentar con éxito una amenaza o acción concreta; 2) la estrategia de obstrucción, cuyo objetivo fue disminuir los recursos de grupos o unidades rivales para comprometer su éxito; 3) la cooptación, destinada a incrementar recursos de poder acudiendo a fuentes externas, mediante la búsqueda de alianzas con poderes rivales, otros gremios y sectores profesionales; 4) el enfrentamiento, donde se puso en riesgo la posición de recursos con objeto de aumentarlos en el futuro, a costa de la posición del grupo o unidad rival, lo que se tradujo en el empleo de la coerción y la violencia; 5) la adaptación, que implicó gastos de recursos con objeto de evitar pérdidas mayores; y 6) la estrategia de penetración (o persuasión), que, aunque presenta características similares a otras, tenía por objetivo debilitar la posición de recursos rivales. A diferencia de las demás estrategias, la persuasión, según Oszlak, elige la acción directa sobre la unidad rival y los aliados potenciales, aunque sin enfrentarlos abiertamente, pues emplea la infiltración ideológica apoyada por los medios de comunicación (Oszlak, 2016: 358-362). A lo anterior debemos agregar, por un lado, la estrategia de modernización, que implicó la defensa discursiva de un empresario agrícola moderno, eficiente y preocupado por el bienestar de sus trabajadores y, por otro lado, la estrategia de la coalición, que permitió la formación de un gran bloque conservador.

\section{LA HETEROGENEIDAD ESTRUCTURAL DEL AGRO EN EL DIAGNÓSTICO TERRATENIENTE}

Entre los factores que ayudan a explicar las estrategias terratenientes para enfrentar la reforma, se encuentra lo que se denominó heterogeneidad estructural de la agricultura chilena. Existe suficiente consenso en señalar que el modelo de desarrollo industrial trajo un aumento paulatino de la modernización y proletarización del campo (trabajadores asalariados) en desmedro del inquilinaje (diversas formas de trabajo rural permanente, con o sin salario, pero con regalías no otorgadas en dinero) y una disminución relativa de la 
mano de obra asalariada estacional (llamados afuerinos, muchos de ellos minifundistas). Sin embargo, esta tendencia, que puede medirse a lo largo de varias décadas incluso a escalas provinciales, no fue masiva. Al llegar la reforma podían encontrarse, incluso en una misma zona, predios bastante modernizados que colindaban con otros de baja tecnologización y escaza proletarización, por lo que se podía diferenciar claramente entre agricultores modernos (empresarios agrícolas) y terratenientes tradicionales.

Los terratenientes tradicionales eran mayormente herederos de la antigua aristocracia criolla, se distinguían por unos cuantos apellidos que conservaban con orgullo algo de su vieja prosapia; en cambio, los autodenominados empresarios agrícolas (identificados por los terratenientes tradicionales como nuevos ricos) alardeaban de impulsar la modernización en los campos. Aunque con el paso de los años las diferencias de cuna se confundían entre ambos grupos, la pertenencia a la clase y formas de explotación de la mano de obra se hacían notar entre ellos, pues algunos testimonios indican un trato más paternalista de parte de los terratenientes tradicionales con sus inquilinos, con quienes cultivaban relaciones de confianza y dependencia. En cambio, algunos terratenientes emparentados con las grandes familias hacenderas acusan de mayor explotación e indiferencia hacia las necesidades de los trabajadores por parte del empresario agrícola (Stabili, 2003: 259-310). Con todo, no existió una mano de obra cultural ni económicamente autónoma: unos y otros, incluidos los pequeños y medianos propietarios, prestaban servicios y dependían estrechamente de la producción y comercialización del fundo o gran propiedad (Bengoa, 1990; Bauer, 1994: 143-170). Aunque es posible hacer mayores precisiones, subdivisiones y ubicarlos geográficamente, nos interesa señalar que en torno a estos dos tipos de terratenientes giraron grandes discusiones, pues se suponía que con la reforma se superaría la agricultura tradicional (Gómez, 1973: 88; 1982: 30-32; Bengoa, 1990, 1996: 30-36; Stabili, 2003) ${ }^{9}$.

A lo anterior se suman diferenciaciones geográficas, étnicas y productivas de diverso tipo que completan este heterogéneo cuadro del agro chileno (Fontaine, 2001: 9-28). Una diferencia significativa para el caso de La Araucanía se halla en el elemento étnico. Tras la ocupación de la región por parte del Estado chileno en la segunda mitad del siglo XIX, sus antiguos soberanos, los mapuche, no habían dejado de reivindicar de diversas formas la recuperación de las tierras y el control del territorio. Sin embargo, esta variable crucial no fue tenida en cuenta por los ideólogos de la reforma (Samaniego \& Ruiz Rodríguez,

9.Las discusiones no se desarrollaban únicamente entre los tecnócratas de la reforma, también existió una aguda crítica de parte de los empresarios agrícolas hacia los terratenientes tradicionales por su rezago frente a la modernización del campo (véanse: Archivo Sociedad Nacional de Agricultura, Santiago, El Campesino, diciembre de 1967, pp. 4-5; abril de 1970, pp. 12, 20, 30-31; junio de 1970, pp. 27-38). 
2007: 325-400). Por otro lado, en el sur de Chile se podían distinguir predios más tecnologizados, trabajadores más especializados y un aumento relativo de la mano de obra permanente con respecto al valle central, pero con grados similares de proletarización (Gómez, 1982: 12-14; Bengoa, 1990; Santana, 2006: 121-148; Almonacid, 2009) ${ }^{10}$.

Conviene destacar, asimismo, que al llegar la reforma podían encontrarse, a rasgos generales, tres tipos de inquilinos, tanto en la zona central como en La Araucanía. En primer lugar, existía una capa minoritaria de inquilinos asalariados y con mayores privilegios, como la utilización de mayor cantidad de tierras del patrón y otros beneficios que variaban según el acuerdo. Este grupo se destacaba como "personal superior» (mayordomos, llaveros, capataces, etc.); eran los llamados inquilinos de a caballo, hombres de confianza que en muchas ocasiones se hacían cargo de las faenas del patrón proveyendo la mano de obra asalariada estacional, cuya remuneración era costeada por estos inquilinos como una forma de subcontratación. Luego, en una categoría más baja, se encontraban los inquilinos tradicionales, con menor acceso a privilegios, con menor salario o sin éste y menor preparación. Y, por último, el grupo más numeroso, los inquilinos más pobres, pertenecientes a las diferentes formas de transición hacia el asalariado 'integral' [y] confundiéndose en parte con el grupo anterior (Santana, 2006: 130). Sobre la capa superior de inquilinos descansaba lo más anquilosado de la tradición hacendal, pues eran los representantes directos de los intereses patronales frente al resto de los trabajadores. Ese atributo les permitía contar con el poder de coerción sobre decisiones incluso privadas de los subalternos (horas de trabajo, descanso y otras formas de control del cuerpo de hombres y mujeres), a quienes administraban como fuerza bruta y arengaban en calidad de capataces (Santana, 2006: 121-145; Tinsman, 2009: 30-33).

Lo expuesto anteriormente comprende aspectos significativos en el desarrollo de las estrategias terratenientes, ya que, como veremos, este cuadro general permitió a los patrones ponderar sus posibilidades considerando el apoyo de la fuerza laboral más afín a sus intereses (como fue el caso de la capa superior del inquilinaje), medir la fuerza social movilizada para buscar su cooptación o resistirla (inquilinos con menos privilegios, campesinos proletarizados y afuerinos) y, a la vez, desplazar a quienes consideraron que era justo expropiarles las tierras (los terratenientes no modernizados). Estas estrategias tuvieron, como expondremos a continuación, un importante éxito.

10.Ad portas de la reforma en la zona central, los trabajadores permanentes comprendían un $48,4 \%$, un $61 \%$ en Concepción y La Frontera y un $61,5 \%$ en Los Lagos, lo que indica una cantidad menor del inquilinaje tradicional en la zona central. Entre 1955 y 1965 el porcentaje de inquilinos disminuyó entre un $9 \%$ y un $9,5 \%$ en las mismas regiones, por lo que el aumento de los trabajadores asalariados fue prácticamente igual a lo largo de toda la zona agrícola (DIRECCIÓN DE ESTADísTiCAS Y CENsos, 1967). 


\section{LAS MOVILIZACIONES: DE LA EXCLUSIÓN A LA INCLUSIÓN SOCIOPOLÍTICA DEL CAMPESINADO}

El aumento de la proletarización campesina a lo largo del siglo xx no vino acompañado de una mejora sustantiva en salarios, tampoco en regalías para los inquilinos de las capas inferiores, ni para los peones estacionales. Esta disparidad respecto de la mano de obra urbana, donde sí se apreció una mejora en las condiciones laborales, no fue para nada casual; reflejó más bien el efecto de un proceso inducido políticamente en el que participó todo el espectro partidista para excluir sociopolíticamente al campesinado de las conquistas de los obreros urbanos. La finalidad de esta exclusión, ejecutada mediante un conjunto de leyes que apuntaron a la desintegración de la sindicalización campesina, fue sostener el proceso de industrialización urbana que puso en marcha el Frente Popular (1936-1941) y que siguieron los demás gobiernos. A cambio de ese apoyo, los partidos de izquierda se comprometieron a no impulsar la reforma agraria ni la sindicalización campesina. Hasta la llegada de Frei, prevaleció la convicción de que la participación política del campesinado, por su enorme peso, modificaría los equilibrios parlamentarios poniendo en jaque no sólo al sector terrateniente, sino al proyecto de modernización industrial del país (Loveman, 1971, 1976; Drake, 1978: 218 y ss.; Gómez Leyton, 2004: 183-200; Santana, 2006: 179) ${ }^{11}$.

Las cosas comenzaron a cambiar en 1958 con la ley de Reforma Electoral, que permitió el voto a los analfabetos y estableció la cédula única, lo que hizo el voto libre y secreto, y redujo el cohecho y el control sobre los electores. Ello significó, por primera vez, la participación libre de los trabajadores de la tierra en la vida político-electoral, de modo que aumentaron significativamente los ciudadanos con derecho a voto. Ese mismo año se derogó la ley de Defensa Permanente de la Democracia (Ley Maldita), terminando así con la proscripción del Partido Comunista y permitiendo su reincorporación en sectores populares.

Más tarde, en 1967 el gobierno de Frei dictó el conjunto de leyes que acompañarían a la reforma agraria: la ley de Reforma Constitucional sobre el Derecho a la Propiedad Privada 16.615, en enero, la ley de Sindicalización Campesina 16.625, en abril, que permitió la sindicalización de los obreros del campo, y la nueva ley de Reforma Agraria 16.640, en julio. Ello facilitó el incremento y la participación activa del campesinado en la reforma agraria y en los procesos electorales. Tal es así que en 1963 sólo había unos 1.500 campesinos sindicalizados mientras que una década más tarde, en 1972, esa cifra

11.Es bien sabido que el precedente de la reforma agraria, la ley 4.496 que en 1928 crea la Caja de Colonización Agrícola, fue de impacto a pequeña escala. A su vez, la ley 8.811 de Sindicalización de Obreros Agrícolas de 1947 creó un sistema que hacía muy difícil la constitución de sindicatos. 
había aumentado a 282.617. Asimismo, entre 1967 y 1973, la participación electoral aumentó significativamente: pasó de 3.074 .000 votantes en las elecciones municipales de 1967, a 4.510.000 en la elección parlamentaria de marzo de 1973 (Gómez Leyton, 2004: 328). Con ello, el número de votantes creció un $46,7 \%$ en apenas siete años.

Esta profundización democrática terminaría por brindar las condiciones para que la democracia chilena caminara hacia una más amplia poliarquía. Con la inclusión definitiva del campesinado en 1967, el sistema político-democrático se volvió plenamente inclusivo y se produjo la disolución político-institucional del pacto de dominación social que sostenía al Estado subsidiario desde los años treinta (Gómez Leyton, 2004: 328).

Así las cosas, en poco tiempo se redujo el control de los sectores conservadores en las zonas rurales, tanto por parte de partidos políticos como de familias latifundistas, estimulando la competencia electoral e incentivando la participación en los partidos, por lo que éstos vieron en los campos un nuevo granero de votos. A ello se sumó el amplio consenso sobre los problemas estructurales que evidenciaba el sector rural, para cuya solución los partidos apostaban por la reforma agraria reclutando al campesinado (Ortega, 1987; Baland \& Robinson, 2008: 1737-1765; Gamboa, 2011: 159-186).

El Partido Demócrata Cristiano (PDC) ya contaba con experiencia debido a su vinculación con el Instituto de Educación Rural (IER) y con otras organizaciones que surgieron luego de la derogación da la Ley Maldita, pero fue el programa social del gobierno de Frei lo que estimuló significativamente su influencia convirtiéndose en un partido hegemónico, por lo menos hasta las parlamentarias de 1965 (Valenzuela, 1995: 55-57). La DC logró constituir tres confederaciones, lo que demostró sus diferencias internas: Triunfo Campesino, Libertad y Sargento Candelaria, que lograron la mayor cantidad de afiliados hasta el gobierno de Allende. Un aumento significativo registró la Confederación Ranquil, de la alianza comunista-socialista, aunque no logró alcanzar a la DC. Más abajo se encontraba el Movimiento de Acción Popular Unitaria (MAPU, fundado en 1969 tras escindirse de la DC), con la Confederación Unidad Obrero Campesina. Por su parte, la derecha, con la confederación Provincias Agrarias Unidas, del Partido Nacional (PN), quedó muy al margen en la competencia por captar votos y movilizar al campesinado. La menor capacidad de la derecha frente a la DC y a la izquierda sería uno de los factores que explicarían por qué, ayudada a partir de fines de 1972 por la DC, abandonó el juego político-democrático presionando a los militares para que tomasen el poder al asumirlo Allende (Garretón \& Moulian, 1983; Valenzuela, 1988).

Las movilizaciones campesinas se desarrollaron en sucesivas oleadas con tendencia hacia una escalada de la violencia. En un primer momento, el movimiento buscó reivindi- 
caciones económico-sociales, como mayores salarios, regalías en tierra para inquilinos, seguridad social y otros. El pliego de peticiones y la huelga fueron las herramientas legales con que contó el campesino para presionar al patrón a partir de la ley de Sindicalización Campesina. Una segunda etapa se abrió con la masificación del proceso expropiatorio provocado a fines del gobierno de Frei. Así, el campesino comenzó a priorizar las tomas de fundos dejando de lado los paros de producción y las huelgas por demandas salariales. Aunque estas dos etapas se materializaron simultáneamente, la primera en adquirir un carácter masivo fue la lucha reivindicativa laboral y luego lo hizo la expropiatoria (Bengoa, 1973: 98; Sánchez Barria, 2012: 6; Avendaño, 2014: 101) ${ }^{12}$.

\section{CUADRO 1}

Confederaciones sindicales campesinas, 1970-1973

\begin{tabular}{llrrrr}
\hline Confederación & Vinculación partidista & \multicolumn{2}{c}{$\mathbf{1 9 7 0}$} & \multicolumn{2}{c}{$\mathbf{1 9 7 3}$} \\
\hline & & $\begin{array}{c}\text { Núm. } \\
\text { afiliados }\end{array}$ & $\begin{array}{r}\text { \% sobre } \\
\text { el total }\end{array}$ & $\begin{array}{c}\text { Núm. } \\
\text { afiliados }\end{array}$ & $\begin{array}{r}\% \text { sobre } \\
\text { el total }\end{array}$ \\
\hline Ranquil & PC-PS (Partido Comunista-Partido Socialista) & 35.328 & 30,10 & 96.254 & 43,00 \\
Triunfo Campesino & PDC (Partido Demócrata Cristiano) & 53.930 & 45,90 & 66.146 & 29,70 \\
Libertad & PDC (Partido Demócrata Cristiano) & 24.854 & 21,15 & 44.260 & 19,80 \\
Sargento Candelaria & PDC (Partido Demócrata Cristiano) & 2.241 & 1,90 & 2.567 & 1,10 \\
Unidad Obrero Campesina & MAPU (Movimiento de Acción Popular Unitaria) & - & - & 14.199 & 6,30 \\
Provincias Agrarias Unidas & PN (Partido Nacional) & 1.129 & 0,96 & 2.181 & 0,90 \\
\hline Total & & $\mathbf{1 1 7 . 4 8 2}$ & $\mathbf{1 0 0}$ & $\mathbf{2 2 5 . 6 0 7}$ & $\mathbf{1 0 0}$ \\
\hline
\end{tabular}

Fuente: Avendaño (2014: 105).

A las movilizaciones de los sindicatos partidistas se sumaron los grupos insurreccionales. En este sentido, un cambio significativo se produjo cuando el Movimiento de Izquierda Revolucionaria (MIR) y el PS plantearon en sus respectivos congresos del año 1967 la vía armada como solución al conflicto de clase y al arribo de una sociedad socialista. Ninguno de los dos contaba con una fuerza guerrillera de importancia ni con políticas internas destinadas a lograr sus objetivos siguiendo dicha vía, sin embargo, la ejecución de una serie de acciones directas por parte del MIR (asaltos a sucursales bancarias y expropiaciones destinadas a «recuperar» para el pueblo lo que la oligarquía habría expropiado a los trabajadores) causaron gran conmoción en la opinión pública y sectores conservadores (Mallon, 2004: 89-132; Railaf et al., 2006; Goicovic, 2010: 59-86; 2012: 25; Bravo, 2012).

12.Según algunos cálculos, en 1965 hubo unas 142 huelgas y 13 tomas; en 1969 las huelgas habían aumentado a 1.127 y las tomas a 148; en 1971 (año de mayor conflicto durante el gobierno de Allende) hubo 1.758 huelgas agrícolas y 1.278 tomas a lo largo del país (MARÍN, 1973: 16; HuERTA, 1989: 337). 
En La Araucanía la situación fue de mayor tensión, favorecida por la alianza entre el movimiento campesino y el indígena. Si bien se registraron tomas de fundo desde el gobierno de Alessandri, las reivindicaciones de tierras por parte de comunidades mapuche se hacen sentir con más fuerza tan pronto se promulga la ley de Reforma Agraria (Correa, Molina \& Yáñez Fuenzalida, 2005: 107), para acentuarse al entrar el gobierno de la UP. Un informe del Instituto de Desarrollo Agropecuario (INDAP) señaló que la afiliación sindical en Cautín se multiplicó significativamente, pasando de 1.648 trabajadores agrícolas asalariados en 1967 a 12.739 en 1971 (Redondo, 2015: 157). A lo anterior se sumó que, a partir de la convergencia entre el MIR y las comunidades mapuche, nacería en la provincia de Cautín el Movimiento Campesino Revolucionario (MCR), que realizó corridas de cerco y ocupaciones de fundos con objeto de recuperar tierras usurpadas de los títulos de merced $^{13}$ y acelerar el cambio revolucionario (Bengoa, 2002: 117-148; Correa, Molina \&Yáñez Fuenzalida, 2005: 108-128; Railaf et al., 2006). El MCR sería la más notoria de las organizaciones que plantearon la vía insurreccional armada. De esta forma, en La Araucanía las movilizaciones estallaban por parte del movimiento partidista (institucionalista) y del movimiento radical (no institucionalista) (Redondo, 2015; Órdenes, 2016).

Así las cosas, los terratenientes pronto se encontraron atrapados en medio de un modelo de modernización burguesa del Estado (Fleet, 1985: 263-313) y el levantamiento de gran parte de sus trabajadores, quienes conformaron, junto a población mapuche en el caso de La Araucanía, un gran movimiento campesino e indígena cuya meta principal fue la reestructuración de la propiedad de la tierra. La vida portentosa y el tipo de sociedad histórica de la que se sentían protagonistas se estaban desmoronando. Cuestión similar ocurría en los centros urbanos, donde los obreros pusieron en jaque la propiedad privada industrial. Los terratenientes tenían que actuar rápido y en contraofensiva a la corriente estatista y al movimiento social.

\section{LAS ESTRATEGIAS TERRATENIENTES EN EL GOBIERNO DE FREI: NEGOCIACIÓN, RESISTENCIAY CONFORMACIÓN DE FUERZAS PATRONALES}

Durante la reforma, las organizaciones patronales utilizaron todos los recursos de poder a su alcance (legales e ilegales, mediáticos y organizacionales) para oponerse a lo que con-

13.Los títulos de merced son escrituras de propiedad rústica que la Comisión Radicadora del Estado dictaminó para el asentamiento y reducción de las comunidades mapuche en las actuales regiones del Biobío, La Araucanía y Los Ríos, tras la ocupación chilena del Wallmapu o País Mapuche, entre 1884 y 1929. 
sideraban expropiaciones indebidas. En su primera etapa, el gobierno Alessandri creo comisiones asesoras que permitieron a los gremios ejercer influencia en el avance de la reforma y en las materias relacionadas con el comercio agrícola. De no haber sido por el terremoto de 1960, que obligó a afectar algunos predios y tierras fiscales, la reforma habría pasado casi desapercibida (Oszlak, 2016: 59-141). No obstante, las discusiones en torno al estancamiento del sector agrícola obligaron a la SNA a la creación del Instituto de Estudios Económicos, destinado a recabar antecedentes para responsabilizar del estancamiento al control.

En esos años también nace en la SNA una preocupación por la unidad gremial. Hasta la década de 1960 las políticas agrarias del modelo desarrollista volcado al desarrollo industrial no contribuyeron a la constitución de alianzas gremiales entre los agricultores de la zona central y sur. La fijación de los precios agrícolas, el apoyo estatal y el transporte de productos favorecieron en mayor medida a los productores y comerciantes del centro, en desmedro de los del sur, lo que generó disputas entre ambos sectores y entre éstos y el Estado, y acercamientos sólo en momentos de tensión, como en los procesos eleccionarios (Garay, 1990; Almonacid, 2009; Pinto \& Órdenes, 2012). Por tal motivo, la cuestión de la unidad gremial fue hasta ese momento un tema pendiente, por lo que a partir de 1962 comenzó a ser recurrente en El Campesino y ElVocero Agrícola (órganos comunicacionales oficiales de la SNA) un llamado en ese sentido ${ }^{14}$.

Como lo anterior no fue suficiente, la SNA también levantó una campaña propagandística con objeto de indicar a la opinión pública su idea sobre la mejor reforma posible. Sostuvo que la tierra debía cumplir una función social, que debía darse el amparo legal al buen agricultor, al empresario agrícola, aquel que ha tecnificado el campo, cumple con las leyes sociales y mantiene relaciones de justicia y protección con sus trabajadores, además de preocuparse por la educación y salubridad ${ }^{15}$. Con este discurso la SNA apuntó a una reforma selectiva que garantizara la seguridad del empresario agrícola, apelando también a la modernización del sector y los intereses de sus trabajadores. Estas premisas iniciales no cambiarían sustantivamente en lo sucesivo.

Con la llegada de Frei, se abrió una nueva etapa en la que aumentó la preocupación por la reforma. Ante el nuevo escenario, la SNA decidió prestar apoyo al Presidente, pero no de manera incondicional, pues supuso que negociando con la DC, más dispuesta a

14.Archivo Sociedad Nacional de Agricultura, Santiago, El Campesino, febrero de 1962, p. 2; mayo de 1967, p. 12.

15.Archivo Sociedad Nacional de Agricultura, Santiago, El Campesino, octubre de 1964, p. 8. Sobre el rol social de la tierra, véase también FonTAINE (2001: 37-54). 
escuchar sus propuestas que los desplazados y disminuidos partidos de derecha, podría evitar una reforma profunda. Apelando a un supuesto incumplimiento del derecho, los terratenientes intentaron, en largas discusiones y reuniones que no tuvieron éxito, negociar con el Ejecutivo y el Congreso los términos con que serían promulgadas las leyes que acompañaron al proceso ${ }^{16}$. Del mismo modo, y con temor a los cambios, la Confederación de la Producción y el Comercio y otros gremios se reunieron en varias oportunidades con Frei para insistir en que la reforma traería desempleo y estancamiento ${ }^{17}$.

Ello provocó un conflicto entre la SNA y el Consorcio Agrícola del Sur (CAS, presente desde la provincia de Malleco a la de Llanquihue), ya que el CAS no aceptaría la disminución de la influencia de la derecha en el proceso. A ello se sumó la falta de apoyo de la SNA a los reajustes de los precios del trigo y leche exigidos por los agricultores del sur, política adoptada por la SNA como una manera de entregar concesiones al Gobierno, que también provocaría un enfrentamiento entre el CAS, el Gobierno y la SNA.

Estos hechos obstaculizaron las negociaciones de la SNA con el Gobierno y los intentos de la SNA de quedar a la cabeza de los gremios patronales a lo largo del país, ya que en el conflicto también fueron afectados los intereses de la Sociedad Agrícola del Norte. A la SNA no le quedó más que continuar con el lobby y sus esfuerzos publicitarios, pero no tuvo éxito (Kaufman, 1967 citado en Sánchez Barria, 2012: 105; Oszlak, 2016: 143-220).

La situación cambiaría nuevamente a partir de 1967. Las nuevas leyes, seguidas de expropiaciones y movilizaciones, convencieron a los terratenientes de que serían afectadas todas las tierras sin excepción, incluidos los predios modernizados. Estaba en marcha un programa que se definía como rápido, drástico y masivo (Fontaine, 2001: 60-65) ${ }^{18}$. Estos hechos contradecían los discursos y promesas presidenciales sobre una reforma selectiva que afectaría sólo a los predios ociosos o mal trabajados, por lo que las organizaciones patronales reformularon posiciones para lograr cohesión y sumar a los terratenientes no organizados (Fontain, 2001: 70-131; Oszlak, 2016: 220-263).

16.Entrevista a Rafael Moreno Rojas, Biblioteca del Congreso Nacional de Chile (BCN), Santiago, 2014, http://historiapolitica.bcn.cl/entrevistas?handle_hc $=10221.1 / 40479 \&$ handle $=10221.1 / 40520$. Las discusiones parlamentarias sobre la ley de Reforma Agraria se encuentran en: BCN, Historia de la Ley, 16.615, Valparaíso, s.f., http://www.bcn.cl/obtienearchivo?id=recursoslegales/10221.3/36897/ 1/HL16615.pdf. Véase también ÓRDENES y DíAZ-DiEGO (2015).

17. Correspondencia de la Confederación de la Producción y el Comercio a Eduardo Frei Montalva, Archivo Casa Museo Eduardo Frei Montalva (ACMEFM), fondo Correspondencia a Eduardo Frei Montalva, Santiago, 13 de junio, 1967.

18.Entrevista a Jacques Chonchol, en CousiÑo y Ovalle (2013: 105). 
La SNA creó comisiones de trabajo en las que participaron proporcionalmente agricultores del norte y del sur. La mesa directiva de la SNA efectuó giras nacionales, organizó charlas, conferencias y encuentros para el fomento y discusión de la unidad terrateniente, a la vez que estimuló la organización de sindicatos de empleadores agrícolas, que permitieron la creación de la Confederación Nacional de Sindicatos de Empleadores Agrícolas de Chile (CONSEMACH) el 12 de julio de 1968 (Oszlak, 2016: 212$228)^{19}$.

En el mismo período, la SNA logró incluir en sus filas al sector privado del gremio de ingenieros agrónomos, con la creación del departamento de Estudios Agronómicos. A esa altura ya existían acercamientos con la Confederación de la Producción y el Comercio, la Cámara de la Construcción y la Sociedad de Fomento Fabril; construyéndose así una resistencia patronal que posteriormente terminaría por unir a todo el sector empresarial. Aunque llena de controversias internas, la unión gremial terrateniente se hacía cada vez más potente, favorecida por la incorporación de la Sociedad Agrícola del Norte y de la Sociedad Agrícola del Sur al Consejo de la SNA en 1968. Asimismo, sacando provecho de la inseguridad en los campos, se buscó transmitir las quejas de los asentados, como la falta de recursos y entrega de tierras, pero sin incluir a este grupo dentro de los socios de los gremios. Bajo la presidencia de Benjamín Matte, al concluir el gobierno de Frei, la SNA incorporó a las asociaciones de pequeños agricultores por primera vez entre sus socios con objeto de sumar fuerzas, pues éstos demandaban recursos para la formación de cooperativas y, sobre todo, la entrega directa de tierras. También, al concluir dicho gobierno se crearon organizaciones para dar participación a las patronas ${ }^{20}$. Así, a través de tales acciones, que contaron con apoyo jurídico, la SNA se puso a la cabeza del movimiento terrateniente y asumió, junto al CAS y la CONSEMACH, la interlocución entre los empresarios agrarios y el Gobierno (Gómez, 1973: 78-80; Hernández, 1973: 47; Barraclough \& Fernández, 1974: 217-218; Oszlak, 2016: 216-263) ${ }^{21}$.

19. Como parte de esas actividades, el abogado de la SNA, Luis Figueroa, recorrió el país en 1967 ofreciendo asesoría para la constitución legal de estos sindicatos. Archivo Sociedad Nacional de Agricultura, Santiago, El Campesino, mayo de 1967, p. 8; junio de 1967, p. 9.

20.Archivo Sociedad Nacional de Agricultura, Santiago, El Campesino, junio de 1970, p. 8; julio de 1970, p. 6.

21.La Confederación Nacional Campesina, de la DC, había exigido a Frei la entrega inmediata de títulos individuales y la constitución de cooperativas, sin pasar primero por el régimen de asentamientos, en tanto que, por el contrario, los sindicatos de la izquierda más revolucionaria preferían las formas de organización colectiva. Correspondencia de la Confederación Nacional Campesina a Eduardo Frei Montalva, ACMEFM, fondo Correspondencia a Eduardo Frei, 15 de noviembre, 1965; Archivo Sociedad Nacional de Agricultura, Santiago, El Campesino, febrero de 1967, pp. 22-24; mayo de 1967, p. 8; junio de 1970, pp. 9, 34-38; agosto de 1969, p. 6. 
En este esfuerzo de unidad gremial, los terratenientes también buscaron apoyo, por último, más allá de las fronteras nacionales, logrando una gran organización patronal a escala latinoamericana en 1967, mediante la constitución de las Asociaciones Agropecuarias Americanas, que surgirían en Chile y otros países como respuesta a las reformas agrarias que se desarrollaban en Latinoamérica. Su principal objetivo fue facilitar el intercambio de información y la coordinación de una agenda común ${ }^{22}$.

Por otro lado, en las diversas reuniones gremiales se sostuvo que la reforma traería mayor estancamiento y pobreza al país, que la única manera de asegurar el desarrollo nacional era mediante el esfuerzo del empresario agrícola y la colaboración del Estado. Se indicaba que dicho esfuerzo lo debían enfrentar conjuntamente patrones y empleados asumiendo una tarea de unidad nacional y modernización agrícola, pues así lo exigía el momento histórico por el que atravesaban sin distinción. Los inquilinos fueron invitados a este proyecto dándoles a entender que junto a sus patrones mejorarían sus expectativas de vida y que la reforma les traería pobreza, pues el Estado no brindaba garantías de que contarían con asesoría y medios técnicos para producir la tierra, ni que ésta pasaría directamente a sus manos a través de títulos individuales de propiedad. En este escenario se levantó un discurso que buscó denostar la reforma agraria y, a la vez, sumar a los trabajadores a un proyecto de modernización "empresarial» terrateniente y de mejora del bienestar nacional (Órdenes \& Díaz-Diego, 2015) ${ }^{23}$.

También se insistió en que la CORA no aplicaba debidamente la ley de Reforma Agraria y que existía un revanchismo político en aquellas provincias donde la derecha había obtenido más votos en las elecciones parlamentarias de 1969. Más aún, considerando que muchas expropiaciones se realizaron como respuesta a tomas de fundos, se sostuvo en discursos emitidos en marchas y en comunicados públicos que la reforma era política, demagógica y no técnica, que lo único que buscaba era el aumento de votos para el Gobierno y no nuevos propietarios (Órdenes \& Díaz-Diego, 2015) ${ }^{24}$.

En el plano discursivo, un argumento recurrente de los sectores conservadores ante las movilizaciones sociales fue achacarlas a la presencia de agitadores profesionales, afuerinos y elementos extraños. Éstos, a través de su acción "perturbadora», serían los causantes de las protestas y tomas. Esto incluía a los agentes de la CORA e INDAP, cuestión que

22.Archivo Sociedad Nacional de Agricultura, Santiago, El Campesino, junio de 1967, p. 9.

23.Archivo Sociedad Nacional de Agricultura, Santiago, El Campesino, febrero de 1967, pp. 22-24; mayo de 1967, p. 8; junio de 1970, pp. 9, 34-38; agosto de 1969, p. 6.

24.Archivo Sociedad Nacional de Agricultura, Santiago, El Campesino, junio de 1970, pp. 6-10; julio de 1970, p. 8. 
no distaba mucho de la realidad (Fontaine, 2001; Cousiño \& Ovalle, 213) ${ }^{25}$. Bengoa (1973) sostuvo que esa fue la lectura gremial de las causas del conflicto social. Ello permitía sostener que los inquilinos en general no se encontraban tan mal y, a la vez, esconder las causas de la agitación social.

Así las cosas, el gremio terrateniente reclamaba con urgencia al Estado la protección del empresariado agrícola, pues éste era considerado como agente fundamental para el desarrollo del agro, así como para el comercio y los trabajadores que de él dependían ${ }^{26}$. No solamente los medios de comunicación de la SNA transmitieron ese mensaje, también los medios conservadores, como El Mercurio y Radio Agricultura, hicieron eco de las demandas gremiales a lo largo del país, además de las políticas adoptadas por la SNA, tendentes a proponer alternativas de solución a los problemas del agro, pero bajo el control empresarial (Barraclough \& Fernández, 1974: 216) ${ }^{27}$.

Más allá del plano discursivo, otra estrategia utilizada por los terratenientes fue que prefirieron, en muchas ocasiones, negociar frente a demandas salariales antes que entrar en confrontación directa con los huelguistas. A pesar de las tensiones suscitadas en un comienzo, como la queja frente a las huelgas y los decretos de aumento salarial y del monto imponible del Servicio de Seguro Social, pronto se produjo una tendencia al acuerdo frente a los pliegos de peticiones por mejoras salariales en diversas partes del país, cuestión que se prolongaría con Allende (Gómez, 1982: 77; Bravo, 2012: 77; Sánchez Barria, 2012: 106-109) ${ }^{28}$.

En los últimos meses del gobierno de Frei, la SNA llegó más lejos con dicha estrategia, dedicándose a llamar a los terratenientes a idear mecanismos que permitieran la participación de los campesinos en la propiedad, en la gestión y en los frutos, con objeto de paralizar la reforma algunos patrones efectivamente pusieron en marcha ese programa (Barraclough \& Fernández, 1974: 214; Fontaine, 2001: 117-120; Cousiño \& Ovalle, 2013: 261). Estos acuerdos permitieron en algunos casos incluso frenar los procesos expropiatorios $^{29}$. José Bengoa, tras observar tal estrategia, señaló:

25.Archivo Sociedad Nacional de Agricultura, Santiago, El Campesino, junio de 1970, pp. 6-10; julio de 1970, p. 8.

26.Archivo Sociedad Nacional de Agricultura, Santiago, El Campesino, abril de 1970, p. 14; junio de 1970, p. 7; agosto de 1970, p. 5.

27.Entrevista a Rafael Moreno Rojas, BCN, Santiago, 2014.

28.Archivo Sociedad Nacional de Agricultura, Santiago, El Campesino, abril de 1970, p. 7; junio de 1970, pp. 6-10; julio de 1970, p. 8.

29. Se dan casos en que los campesinos de un predio solicitan a CORA la expropiación, y el patrón, en lugar de responder con represalias o desmantelando el fundo, lo hace con ofertas tentadoras: mejoras sustanciales en 
En este momento, ningún patrón agrícola pone dificultades para solucionar un pliego de peticiones y la mayoría de las reivindicaciones esenciales ya están adquiridas. El objeto implicito de la ley de sindicalización, de 'modernizar' al terrateniente - a lo menos en este aspecto- se ha logrado con éxito (1973: 93).

En La Araucanía, la situación intentaba resolverse de manera similar. En julio de 1970, cuando se hablaba de la toma de unos 22 fundos, la SNA sostenía que los patrones se mostraban dispuestos a dialogar y atender los petitorios salariales, pero los peones, instigados por «elementos extraños» (de fuera de los fundos), eran confundidos y terminaban participando en disturbios ${ }^{30}$. En los dos grandes conflictos laborales registrados en la provincia de Cautín, en 1969 y 1971, ambos a cargo de la Federación de Sindicatos de Trabajadores Agrícolas Presidente Frei, se llegó a acuerdo sobre los pliegos de peticiones, que afectaron a trabajadores de más de 120 y 240 fundos, respectivamente (Redondo, 2015: 158) ${ }^{31}$. A pesar de que con esta estrategia se intentaba restar importancia al movimiento mapuche y mostrar la «buena voluntad» de los patrones, las tomas de fundos en demanda de tierra (caso en el que los patrones no estarían dispuestos a ceder) también coincidieron con movilizaciones por demandas salariales, por lo que se debía actuar con cautela.

En esa dirección, El Campesino y ElVocero Agrícola se encargaron de publicar las leyes sociales, invitando a los agricultores a cumplirlas. Junto a ello, la SNA insistía en que los terratenientes se estaban haciendo cargo mejor que el Estado del bienestar de sus trabajadores, al tiempo que recalcaba que quedaba bastante por hacer ${ }^{32}$. En ese sentido, también se levantó una propaganda bajo la engañosa consigna ;No al patrón estatal!, indicando que los terratenientes estaban dispuestos a dialogar frente a las demandas salariales, además de entregar mejores garantías económicas que lo que podía ofrecer el Estado en los asentamientos, pues éste supuestamente no haría nuevos propietarios, quedando los trabajadores a su arbitrio. Así se ponían en tela de juicio los supuestos básicos de la reforma (Gómez, 1973: 80-81; Hernández, 1973: 52-57) ${ }^{33}$.

los salarios (que por supuesto exceden a los anticipos que se entregan en el área reformada), sistemas de anticipación (que van desde la gestión hasta la propiedad de los predios), etcétera. En estas condiciones los campesinos se retractan de su petición inicial a CORA (GómEZ, 1973: 78).

30.Archivo Sociedad Nacional de Agricultura, Santiago, El Campesino, julio de 1970, p. 8.

31.Para el conflicto de 1969, Archivo Biblioteca Galo Sepúlveda, Temuco, El Diario Austral, 14, 16 y 23 de febrero, 6, 19, 22 y 28 de marzo de 1969; para el conflicto de 1971, ibid., 24 de marzo, 2 y 7 de abril de 1971.

32.Archivo Sociedad Nacional de Agricultura, Santiago, El Campesino, agosto de 1970, pp. 36-39. 33.Archivo Sociedad Nacional de Agricultura, Santiago, El Campesino, junio de 1970, pp. 6-10, julio de 1970 , p. 8. 
Sin duda, el mejoramiento de las condiciones laborales, tanto gracias a las políticas estatales como a las negociaciones colectivas, trajo cambios que favorecieron al empresario agrícola. Con la nueva legislación aumentó el salario mínimo y la sustitución del pago de salario en regalías por el pago en efectivo, lo que trajo una disminución del inquilinaje tradicional y la mediería, pues de unos setenta mil inquilinos no asalariados que existían en 1965, se llegó a unos treinta y cinco mil en 1970. Con ello se absorbió parte de la presión del movimiento campesino, pero sin afectar su movilidad social. A su vez, el aumento en salarios fue compensado con una mayor mecanización y racionalización del trabajo (facilitados por importaciones y créditos blandos a costa del Estado), lo que provocó el despido masivo de trabajadores estables y la sustitución de parte de los trabajadores temporales. El desempleo agrícola era una de las características más relevantes del período, y alcanzaba a fines de la administración Frei la cifra récord de más del 30\% (Hernández, 1973: 47).

Con tales transformaciones se lograban varios objetivos del proyecto modernizante de interés empresarial. En primer lugar, aumentó el poder de consumo mediante el aumento de salarios y la incorporación de aquellos campesinos que dejaban de producir sus propios alimentos tras transformarse en asalariados. En segundo lugar, disminuyó la agitación campesina al incorporar los trabajadores estables a los intereses de la empresa patronal. Y, en tercer lugar, al garantizar el trabajo estable y con mejores salarios, se desvinculó a una parte de los trabajadores de la lucha directa contra los propietarios agrícolas, ganándolos a las fuerzas del patrón. Todo ello, en medio del arbitrio y subvenciones estatales (Hernández, 1973: 47; Barraclough \& Fernández, 1974: 214) ${ }^{34}$.

Obviamente, estos acuerdos no estuvieron exentos de perturbaciones en un ambiente de tanta tensión y donde la negociación colectiva era una práctica hasta entonces extraña en los fundos. Más aún cuando las reivindicaciones salariales comenzaron a cruzarse con expropiaciones y tomas de fundos por demandas de tierra.

La situación se complicó aún más cuando se generalizaron las tomas, lo que desembocó en numerosas ocasiones en la organización de patrullas gremiales de autodefensa y recuperación de predios al comprobar que las autoridades no respondían a sus demandas. Primero vinieron los atrincheramientos, luego los comités de retoma y las guardias blancas, que posteriormente favorecerían la formación de grupos de extrema derecha. Tanto en la zona central como en el sur, algunos patrones tomaron la justicia por sus manos y lo hicieron, muchas veces, de manera desmedida y con ensañamiento, causando varias muertes ${ }^{35}$. véanse, por ejemplo, BENGOA (1973), FonTAINE (2001: 115-131) y Tinsman (2009: 206-218). 
Este tipo de actividades mostraron una capacidad significativa de coerción que requirió del control de una importante fuerza de choque; trabajadores capaces de mostrar colaboración y lealtad al patrón. Los testimonios indican que aquel segmento que hemos identificado como capa superior de inquilinos o inquilinos de a caballo, junto a los mocitos (empleados de casa) y peones contratados para ese efecto, defendieron con armas los predios en que trabajaban. Sobre todo en el caso de los inquilinos acomodados y de los mocitos, como habían nacido y vivido como grupos selectos, con privilegios y distinciones superiores, muchos no estuvieron dispuestos a cambiar su estilo de vida para defender una causa que percibían ajena e inconveniente a sus intereses, y se situaron, por tanto, más próximos a los intereses terratenientes que a los intereses campesinos ${ }^{36}$. Aunque en ocasiones los patrones no contaron con esta ayuda y recibieron sólo la colaboración de amigos y cercanos, las movilizaciones campesinas reflejaron las fisuras en el interior de la clase trabajadora, mostrando quiénes estaban con el patrón y quiénes no (Railaf et al., 2006; Tinsman, 2009; Bravo, 2012: 83) ${ }^{37}$.

Así ocurrieron hechos de violencia donde estallaron refriegas y verdaderas batallas campales entre las fuerzas del patrón y las fuerzas del movimiento campesino, los cuales involucraron también a agentes de la CORA y Carabineros. Para el caso de la zona central, hechos de este tenor se registraron en Lampa, en la Hacienda Lo Barros, en los fundos El Porvenir y Los Cristales, en Curicó, en el fundo Santa Marta, en Longotoma, en el fundo Pailimo, en Santa Cruz, en el fundo La Piedad en Longaví, en la zona de Parral, entre varios otros (Gómez, 1982: 75-94; Fontaine, 2001: 75-130; Tinsman, 2009; Cousiño \& Ovalle, 2013; Avendaño, 2014: 109-110).

Un escenario más complejo se produjo en La Araucanía cuando el movimiento campesino e indígena comenzó a tomarse los fundos desafiando a los escuadrones de inquilinos que, a diferencia de otras partes del país, comprendieron empleados katripache (no mapuche) a los que, en ocasiones, se sumaron trabajadores mapuche. Ello nos remite a dos planos de una misma realidad: por un lado, la aculturación de un pueblo que en plena dominación poscolonial se habría enfrentado entre sí por el derecho de terceros sobre tie-

36. No contamos con testimonios donde los propios terratenientes señalen la colaboración armada de sus trabajadores en la defensa de los fundos. En tales círculos éste sigue siendo un tema tabú, a la vez que se achaca la violencia sólo a los agitadores de izquierda; sin embargo, los terratenientes indican enfrentamientos con la colaboración de sus trabajadores más leales, pero sin el uso de armas (CousiÑo \& Ovalle, 2013). No obstante, existen bastantes testimonios de ex miristas y otros que confirman tales enfrentamientos (RAILAF et al., 2006; BRAVO, 2012: 83, 89; entrevista a Chonchol, en Cousiño \& Ovalle, 2013: 108).

37.Archivo Sociedad Nacional de Agricultura, Santiago, El Campesino, abril de 1970, p. 13; junio de 1970, pp. 6-10; agosto de 1970, p. 6. 
rras que habían sido arrebatadas militarmente por el Estado apenas noventa años antes y, por otro lado, la decisión de miembros de este mismo pueblo de postergar sus intereses étnicos priorizando lealtades hacia sectores katripache, más próximos a otros intereses y otras vivencias, renunciando así a su lealtad hacia los mapuche, con quienes compartían experiencias vinculadas a la memoria y filiación étnica ${ }^{38}$.

Sea como fuere, el elemento étnico añadió en La Araucanía una cuota mayor de complejidad al conflicto. Por ejemplo, cuando comenzaron las tomas que afectaron al fundo Chiguaihue, en la provincia de Malleco, en agosto de 1969, concurrió un grupo numeroso de dueños de fundo y colaboradores provenientes de Traiguén, Victoria, Collipulli, Angol y Los Ángeles con objeto de desalojar a los ocupantes (Correa, Molina \& Yáñez Fuenzalida, 2005: 118). Entre los factores que motivaron el operativo en la zona, destacan la masiva presencia mapuche y los fundamentos etnoterritoriales de su demanda, que ponían en jaque el concepto de propiedad privada de manera más amenazante aún que la propia reforma agraria. Poco después, los terratenientes organizaron comités de retoma, igual como en la zona central.

Esta alianza patrón-inquilino generó diversas formas de resistencia. No cabe duda de que muchas marchas y protestas se realizaron gracias a muestras de lealtad al patrón por parte de algunos empleados. Estos eventos reunían en distintas partes a inquilinos, sindicatos de empleadores agrícolas y organizaciones gremiales ${ }^{39}$. Las protestas más significativas se llevaron a cabo en Santiago frente al Palacio de La Moneda y al Ministerio de Agricultura, donde un grupo de manifestantes llegó hasta la huelga de hambre exigiendo que se restituyeran las tierras al patrón ${ }^{40}$.

No obstante, no todo se tradujo en el choque directo y demás estrategias descritas en párrafos anteriores, pues los terratenientes agotaron todos los recursos de poder a su alcance, entre ellos, el recurso legal. Los terratenientes contaron con un grupo selecto y cerrado de abogados que formaban parte de las redes familiares y políticas de mayor confianza. Sin embargo, amarrados por las leyes de la reforma agraria y la presión de las autoridades, este contingente de abogados tuvo un éxito relativo, tanto en los tribunales

38.Para el caso de La Araucanía, resultan interesantes, entre otros, una serie de testimonios de ex militantes del MCR, quienes, en su casi totalidad, recuerdan enfrentamientos con trabajadores leales a sus patrones (RAILAF et al., 2006). Véanse también al respecto BENGOA (2002), MALLON (2004: 94104), Correa, Molina y YÁÑEZ FuenZalida (2005) y Linfati (2013: 45-58), entre otros.

39.Archivo Sociedad Nacional de Agricultura, Santiago, El Campesino, abril de 1970, p. 14; junio de 1970, p. 7.

40.Archivo Sociedad Nacional de Agricultura, Santiago, El Campesino, agosto de 1970, p. 6; Entrevista a Rafael Moreno Rojas, BCN, Santiago, 2014. 
como en las negociaciones con los responsables de las tomas. La Corte Suprema, por su parte, a pesar de sus vínculos con sectores conservadores, decidió acatar los dictámenes de la CORA (Amunátegui, 2011). Así, por ejemplo, para el caso de la zona central, uno de los abogados más destacados, que, sin embargo, llevaría sin mucho éxito varias causas de tierra, fue el parlamentario Mario Arnello (Fontaine, 2001: 125). En La Araucanía, otros miembros de familias terratenientes, abogados y activos en la defensa de casos de toma y expropiación de fundos fueron Víctor Carmine, diputado del Partido Nacional de 1969 a 1973, y Alfonso Podlech, fiscal militar después durante la dictadura. Ambos se verían envueltos de distinto modo en hechos de violencia según Mallon (2004: 101), Bravo (2012: 87-89) y Linfati (2013: 49). En Llanquihue, la situación fue más favorable pues la Corte de Apelaciones mostró un compromiso con los terratenientes en este tipo de causas (Sánchez Barria, s.f.).

Algunos testimonios indican que ciertos terratenientes contaron, además, con el apoyo de parte del clero. En su tarea de persuadir a los ocupantes para que entregaran los fundos tomados, algunos sacerdotes en sus sermones dominicales, e incluso en visitas a casas particulares, anunciaron las penas del infierno para los ocupantes ilegales (Bravo, 2012: 87, 103).

El gobierno de Frei concluiría con un distanciamiento entre los gremios terratenientes y el Gobierno, pero sin llegar a una ruptura absoluta; distanciamiento que se acentuó con el anuncio de recortes presupuestarios para créditos agrícolas y otros en el encuentro FISA 1969, así como con la dictación de la ley Aylwin, que agilizaría el proceso expropiatorio a partir de 1970. Sin embargo, lo anterior vino acompañado de un reencuentro entre la SNA y el Partido Nacional, que se vio reforzado con motivo de la elección presidencial de 1970 (Oszlak; 2016: 248-263).

\section{EL GOBIERNO DE ALLENDE: RADICALIZACIÓNY DESENLACE}

Durante el período eleccionario, las organizaciones patronales prepararon, a diferencia de en ocasiones anteriores, un documento sobre un proyecto de reforma agraria que presentaron a todos los candidatos con excepción de Allende, por alejarse de lo que consideraban debían ser cambios moderados. Evidentemente, la victoria luego de Allende ensombreció el panorama para los dueños de fundos (Oszlak, 2016: 251-253).

El primer año de gobierno popular, la SNA ideó un conjunto de estrategias que le permitieron ensanchar la coalición con los sectores conservadores, mientras se mantenía a la espera de definir la inevitable confrontación con la UP. Al tiempo, las organizaciones 
terratenientes trataban con el Gobierno, no sin tiranteces, mediante petitorios, reuniones y telegramas. Lograron incluir en sus filas a agricultores del norte, como a los de Atacama, tras la creación de su federación provincial, que formó parte de la CONSEMACH. Al mismo tiempo, se apreciaba un intercambio más fluido con el $\mathrm{PN}$ y los gremios industriales y comerciales (Campero, 1984: 40-61; Oszlak, 2016: 265-288) ${ }^{41}$.

Como la toma de fundos se radicalizaba en La Araucanía, la CONSEMACH y la CAS intentaron demandar al Gobierno ante el Poder Judicial y entregaron «informes» al Ministerio de Defensa Nacional por motivos de «seguridad nacional». De esta forma se hizo evidente el acercamiento de estas organizaciones con los militares, en tanto la SNA siguió con su postura moderada en ese primer año (Barraclough \& Fernández, 1974: 216; Oszlak, 2016: 273).

En el plano comunicacional, la SNA sacó ventaja de los disensos al interior de la UP haciendo más notorios los conflictos para así deslegitimar la tarea gubernamental, pero sin modificar sustancialmente las demás estrategias del Gobierno anterior (Oszlak, 2016: 271).

Por otro lado, la constitución de los tribunales agrarios (contemplados previamente en la ley 16.640, pero hasta ese momento sin formación), permitió a los terratenientes intervenir de mejor manera los juzgados para frenar las expropiaciones. Los responsables de la reforma criticaban estos tribunales como verdaderos consejos de honorables, formados por magistrados, autoridades y profesionales locales (Hernández, 1973: 57; Barraclough \& Fernández, 1974: 216).

Sin embargo, nada fue obstáculo para que continuara la defensa violenta al interior de los fundos. Con la radicalización del conflicto, protagonizado por el MIR y el MCR, surge en 1971 la organización de ultra derecha Frente Nacionalista Patria y Libertad, estrechamente ligada al PN, y el mismo año en La Araucanía, el Comando Rolando Matus (CRM), también ligado a los dos anteriores. Estas organizaciones, que en muchas ocasiones apoyaron a los comités de retoma y a las guardias blancas, provocarían enfrentamientos, heridos y varias muertes de mapuches y campesinos (Mallon, 2004: 89132; Correa, Molina \&Yáñez Fuenzalida, 2005: 171-176; Linfati, 2013: 45-58) ${ }^{42}$. En un

41.Archivo Sociedad Nacional de Agricultura, Santiago, El Campesino, noviembre de 1970, p. 7.

42.Archivo Biblioteca Galo Sepúlveda, Temuco, El Diario Austral, 25 de diciembre de 1970, p. 5; 17 de mayo de 1972, p. 1; 3 de abril de 1973, p. 7. Entre 1972 y 1973 se recibieron en Valparaíso varios cargamentos de armas provenientes de Brasil, en cajas de maquinaria agrícola y otros productos que fueron importados por la firma del senador del PN y empresario agrícola, Pedro Ibáñez Ojeda, a fin de equipar a Patria y Libertad (MoNIZ, 2003). 
comienzo estas actividades fueron clandestinas, pero al comprobar que Allende no hacía uso de la fuerza pública a pesar de las denuncias patronales y que en La Araucanía había llegado a acuerdos con los mapuche para aumentar la entrega de tierras ${ }^{43}$, las organizaciones patronales decidieron, mediante comunicado público, hacer explícita la legítima defensa de sus bienes con los medios que sea racionalmente necesario ${ }^{44}$.

La situación tomó un viraje a partir de enero 1972, cuando la SNA se une al Frente Nacional del Área Privada (FRENAP), creado en diciembre del año anterior por la Confederación de la Producción y el Comercio, la Sociedad de Fomento Fabril, la Confederación del Comercio Detallista y la Confederación de la Pequeña Industria y Artesanos. Con el FRENAP los gremios patronales en su conjunto giraron desde una oposición moderada a la confrontación directa (Campero, 1984: 62-65; Oszlak, 2016: 288-289).

Con objeto de boicotear la economía, los terratenientes paralizaron sus actividades productivas (Oszlak, 2016: 296-299), en tanto que en los medios de comunicación controlados por los gremios comenzó a ser recurrente un discurso antagonista que antes no había sido perfilado tan nítidamente. El marxismo o comunismo, representados por el monopolio estatal en manos del Gobierno y la coalición de partidos de izquierda, fue presentado como un oponente de origen foráneo al que se debía resistir. Así se afirmaba en la dirigencia gremial un carácter nacionalista y una identidad patriótica. La lucha que a partir de ese momento se fue dando fue cada vez menos por evitar que el Gobierno cometiera "excesos» en su afán de cambio social para convertirse, cada vez más, en un lucha por la restitución de un "orden» social y político «universal», que fue definido como vulnerado y al que se denominó democracia, tradición, valores nacionales, libertad, etc. Desde este punto de vista la UP constituía un adversario ilegítimo (Campero, 1984: 62).

La SNA se uniría a este discurso a raíz del paro camionero de octubre de 1972, conformando con el resto de los gremios el Comando Nacional de Defensa Gremial, que elaboró el llamado Pliego de Chile documento que unificaba las demandas de todas las organizaciones en conflicto. Los gremios declararon que no aceptarían sino una solución de conjunto (Campero, 1984: 71). A esas alturas el FRENAP ya apelaba a los militares para la restauración del orden ${ }^{45}$. La estrategia final terrateniente sería la desestabilización del régimen junto a la fuerza de la gran coalición gremial y política (Campero, 1984: 73-88).

43.Archivo Biblioteca Galo Sepúlveda, Temuco, El Diario Austral, 17 al 22 de diciembre de 1969; 17 al 20 de diciembre de 1970 .

44.Archivo Sociedad Nacional de Agricultura, Santiago, El Campesino, mayo de 1971, p. 15. 45.Archivo Sociedad Nacional de Agricultura, Santiago, El Campesino, agosto de 1972, p. 2. 


\section{CONCLUSIONES}

El análisis de las estrategias señaladas permite sostener que el desafío presentado por la reforma fue enfrentado por los terratenientes de acuerdo a una lectura del contexto que cambiaría según el ritmo de los acontecimientos. Es posible apreciar cinco períodos de corta duración, separados por momentos de inflexión que obligaron a reconfigurar las estrategias. El primero partiría en 1962 con la reforma agraria de Alessandri, para concluir en 1964, con un balance positivo para los agricultores. Al asumir Frei el Gobierno, se abriría un nuevo período, caracterizado por los intentos de negociación de los términos en que serían promulgadas las nuevas leyes, a la vez que se hizo más notoria una fuerte campaña propagandística sobre el tipo de reforma exigida al Estado, el desarrollo rural y la reivindicación del empresariado agrícola, todo ello apoyado con estudios técnicos. Sin embargo, las pugnas entre las organizaciones patronales y la divergencia de sus intereses y estrategias obstaculizaron los intentos de frenar una reforma que se atisbaba profunda.

En 1967 comenzaría una nueva etapa. Las nuevas leyes, seguidas de tomas de fundos y expropiaciones, obligaron nuevamente a los gremios a repensar sus movimientos. Se desarrollaron lo que hemos denominado fuerzas patronales. Sin dejar de lado la campaña propagandística ni las infructuosas negociaciones con el gobierno de Frei, se crearon y reforzaron alianzas entre los gremios agrarios, industriales y profesionales. A la vez, los terratenientes, junto con avanzar tibiamente en la respuesta de petitorios de sus empleados, lograron el apoyo de sus trabajadores más fieles para la resistencia de tomas y expropiaciones, mientras aprovechaban sus contactos y redes de influencia en el ámbito judicial.

Con la llegada de la UP se abriría una cuarta etapa, un corto período de menos de dos años, caracterizado por una oposición moderada al Gobierno por parte de la SNA, al mismo tiempo que las tomas cada vez más frecuentes crispaban los nervios en el campo y las organizaciones agrícolas ampliaban sus alianzas con el resto de los gremios patronales, pasando a constituir una gran coalición (FRENAP) que se caracterizó por su oposición antimarxista. A partir del histórico paro de los camioneros, en octubre de 1972, coincidente además con un período de expropiaciones industriales, comenzó una quinta etapa en la reforma agraria caracterizada por la oposición frontal de los terratenientes y el descontento vox populi de importantes sindicatos campesinos frustrados por el escaso reparto de tierras.

Como hemos visto, la resistencia de los terratenientes del centro-sur de Chile a la reforma agraria estuvo llena de matices, sus estrategias fueron múltiples y complejas, en un 
contexto en el que sus recursos de poder no brindaron los resultados esperados, en un tiempo, especialmente durante el gobierno de Allende, que les jugó claramente en contra. Aun así, la resistencia violenta de los terratenientes no puede considerarse significativa hasta que, durante el Gobierno allendista, las tomas ilegales se masificaron. De esta forma, se aprecia con claridad que los agricultores privilegiaron la contención del conflicto a la acción violenta, con lo que mostraron una importante capacidad de articulación gremial y negociación político-laboral a escala provincial y nacional.

\section{REFERENCIAS}

Almonacid, F. (2009). La agricultura chilena discriminada (1910-1960). Madrid: Consejo Superior de Investigaciones Científicas.

AmunÁtegui, A. (2011). El protagonismo político del Poder Judicial entre los años 1965 y 1973. Revista de Derecho de la Pontificia Universidad Católica de Valparaíso, (36), 619-663.

AvENDAÑo, O. (2014). Los partidos frente a la cuestión agraria en Chile, 1967-1973. Revista de Ciencia Politica, 52 (1), 93-122.

Baland, J.-M. \& Robinson, J. A. (2008). Land and Power: Theory and Evidence from Chile. American Economic Review, 98 (5), 1737-1765.

BARRAClough, S. \& FernándeZ, J. A. (1974). Diagnóstico de la reforma agraria chilena. México: Siglo XXI.

BAUER, A. J. (1994). La sociedad rural chilena: Desde la conquista española a nuestros días. Santiago: Andrés Bello.

BENGOA, J. (1973). Movilización campesina: Análisis y perspectivas. En S. BARRACLOUGH et al., Chile: Reforma Agraria y Gobierno Popular (pp. 96-101). Buenos Aires: Periferia.

BengoA, J. (1990). Historia Social de la Agricultura Chilena. 2: Haciendas y Campesinos. Santiago: Sur.

BENGOA, J. (1996). La comunidad perdida: Ensayos sobre identidad y cultura: Los desafios de la modernización en Chile. Santiago: Sur.

BengoA, J. (2002). Historia de un conflicto: El Estado y los mapuches en el siglo XX. 2. ${ }^{\mathrm{a}}$ ed. Santiago: Planeta/Ariel.

Bravo, J. M. (2012). De Carranco a Carrán: Las tomas que cambiaron la historia. Santiago: LOM.

CAmpero, G. (1984). Los gremios empresariales en el período 1970-1983. Santiago: Instituto Latinoamericano de Estudios Transnacionales.

Correa, M., Molina, R. \& YÁÑez FuenZalida, N. (2005). La Reforma Agraria y las tierras mapuches: Chile 1962-1975. Santiago: LOM. 
Cousiño, A. \& Ovalle, M. A. (2013). Reforma Agraria chilena: Testimonios de sus protagonistas. Chile: Memoritter.

DíAZ-Diego, J. \& ÓRDENES, M. (2016). Sujetos esquivados, memorias evadidas: Sesgos antropológicos e historiográficos en torno a los dueños de la tierra durante la reforma agraria chilena. História Unisinos, 20 (2), 163-177.

Dirección de Estadísticas y Censos (1967). IV Censo Agrícola. Santiago: Dirección de Estadísticas y Censos.

Drake, P. W. (1978). Socialism and Populism in Chile, 1932-1952. Urbana: University of Illinois Press.

Fleet, M. (1985). The Rise and Fall of Chilean Christian Democracy. Princeton: Princeton University Press.

FonTAINE, A. (2001). La tierra y el poder: Reforma agraria en Chile (1964-1973). Santiago: Zig-Zag.

GamBoA, R. (2011). Reformando reglas electorales: La cédula única y los pactos electorales en Chile (1958-1962). Revista de Ciencia Politica, 31 (2), 159-186.

Garay, C. (1990). El Partido Agrario-Laborista: 1945-1958. Santiago: Andrés Bello.

Garretón, M. A. \& Moulian, T. (1983). La Unidad Popular y el conflicto político en Chile. Santiago: Minga.

Goicovic, I. (2010). Transición y violencia política en Chile (1988-1994). Ayer, (79), 5986.

GoIcovic, I. (2012). Movimiento de Izquierda Revolucionaria. Santiago: Escaparate.

GoIcovic, I. (2015). Trabajadores agrícolas y procesos políticos en el valle del Choapa (Chile, 1957-1975). Esboços, 22 (33), 102-127.

Gómez Leyton, J. C. (2004). La frontera de la democracia: El derecho de propiedad en Chile, 1925-1973. Santiago: LOM.

GómEZ, S. (1973). El rol del sector agrícola y la estructura de clases: Consideraciones sobre el caso chileno. En S. BARRAClough et al., Chile: Reforma Agraria y Gobierno Popular (pp. 74-91). Buenos Aires: Periferia.

Gómez, S. (1982). Instituciones y procesos agrarios en Chile. Santiago: Facultad Latinoamericana de Ciencias Sociales/Consejo Latinoamericano de Ciencias Sociales.

Guardino, P. F. (1996). Peasants, Politics, and the Formation of Mexico's National State. Guerrero, 1800-1857. Stanford: Standford University Press.

HERnÁNDEZ, S. (1973). El desarrollo capitalista del campo chileno. En S. BARRAClOUGH et al., Chile: Reforma Agraria y Gobierno Popular (pp. 37-59). Buenos Aires: Periferia.

Huerta, M. A. (1989). Otro agro para Chile: Historia de la Reforma Agraria en el proceso social y politico. Santiago: CISEC-CESOC.

Linfati, A. (2013). Violencia patronal durante el proceso de Reforma Agraria en las comunas de Lumaco, Traiguén y Victoria: Los «comités de retomas» y acciones violen- 
tas de grupos opositores a la Unidad Popular (1970-1973). Historia en Movimiento, 2 (9), 45-58.

Loveman, B. (1971). El campesino chileno le escribe a su Excelencia. Santiago: ICIRA. Loveman, B. (1976). Struggle in the Countryside: Politics an Rural Labor, in Chile, 19171973. Bloomington: Indiana University Press.

Mallon, F. E. (1994). The Promise and Dilemma of Subaltern Studies: Perspectives from Latin American History. The American Historical Review, 99 (5), 1491-1515.

Mallon, F. E. (2003). Campesino y Nación: La construcción de México y Perú poscoloniales. México: Centro de Investigaciones y Estudios Superiores en Antropología Social.

MALlon, F. E. (2004). La sangre del copihue. Santiago: LOM.

MARÍN, J. C. (1973). Las tomas, 1970-1972. Santiago: ICIRA.

Moniz, L. A. (2003). Brasil y los golpes en Bolivia, Uruguay y Chile 30 años después. La Onda Digital [en línea]. http://www.laondadigital.uy/LaOnda/101-200/152/B2.htm

ÓRDENES, M. \& DíAZ-Diego, J. (2015). Discurso y movimiento gremial terrateniente durante la reforma agraria de Eduardo Frei Montalva en el centro y sur de Chile, 19641970. Revista de História Regional, 20 (1), 47-75.

ÓRDENES, M. (2016). Conflicto mapuche-campesino en la Araucanía: Un análisis a partir de la Estructura de Oportunidades Políticas (EOP), 1967-1973. Izquierdas, 26 (1), 126-168.

ORTEGA, E. (1987). Transformaciones agrarias y campesinado. Santiago: Corporación de Investigaciones Económicas para Latinoamerica.

OszLAK, O. (2016). La trama oculta del poder: Reforma agraria y comportamiento politico de los terratenientes chilenos, 1958-1973. Santiago: LOM.

PINTO, J. \& ÓRDENEs, M. (2012). Chile una economía regional en el siglo XX: La Araucanía (1900-1960). Temuco: Universidad de La Frontera.

Purnell, J. (1999). Popular Movements and State Formation in Revolutionary México: The Agraristas and Cristeros of Michoacán. Durham: Duke University Press.

RAILAF, R. et al. (2006). A desalambrar: Historias de mapuches y chilenos en la lucha por la tierra. Santiago: Ayun.

REDONDO, J. (2015). Las tomas de fundos en la provincial de Cautín (Chile), 1967-1973. Cuadernos de Historia, (42), 153-178.

Samaniego, A. \& Ruiz Rodríguez, C. (2007). Mentalidades y políticas Wingka: Pueblo mapuche, entre golpe y golpe. Madrid: Consejo Superior de Investigaciones Científicas.

SÁNCHeZ BARRIA, F. (2012). Política nacional, conflictos locales: Los propietarios agrícolas de la provincia de Llanquihue y la movilización rural en la Reforma Agraria chilena. Revista Austral de Ciencias Sociales, (23), 101-131. 
SÁNCHEZ BARRIA, F. (s.f.). Criminalizando la protesta rural: Las estrategias judiciales de los propietarios agrícolas de la provincia de Llanquihue y la Reforma Agraria de la Unidad Popular. Documento inédito.

SANTANA, R. (2006). Agricultura chilena en el siglo XX. Santiago: CEDER/Centro de Investigaciones Diego Barros Arana.

STABILI, M. R. (2003). El sentimiento aristocrático: Elites chilenas frente al espejo (18601960). Santiago, Andrés Bello.

Tinsman, H. (2009). La tierra para el que la trabaja. Santiago: LOM/Centro de Investigaciones Diego Barros Arana.

Valenzuela, A. (1988). El quiebre de la democracia en Chile. Santiago: Facultad Latinoamericana de Ciencias Sociales.

VAleNZUELA, S. (1995). Orígenes y transformaciones del sistema de partidos en Chile. Estudios Públicos, (58), 5-80.

Weber, M. (1985). Sobre la teoría de las ciencias sociales. Barcelona: Planeta-Agostini.

Wright, T. (1982). Landowners and Reform in Chile: The Sociedad Nacional de Agricultura, 1919-1940. Urbana: University of Illinois Press. 